\title{
Facile Method for Preparation of Porous Carbon Derived from Biomass for High Performance Supercapacitors
}

\author{
Yao Lu, Fen Xu*, Lixian Sun*, Yi Wu, Yongpeng xia, Xinran Cai, Ningkuan Zhong, Huanzhi Zhang, \\ Bin Li, Hailiang Chu
}

Guangxi Key Laboratory of Information Materials, Guangxi Collaborative Innovation Center of Structure and Property for New Energy and Materials, School of Material Science and Engineering, Guilin University of Electronic Technology, Guilin, 541004, P. R. China

*E-mail: xufen@guet.edu.cn, sunlx@guet.edu.cn

doi: $10.20964 / 2019.12 .54$

Received: 2 July 2019 / Accepted: 17 September 2019 / Published: 29 October 2019

\begin{abstract}
A facile method is adopted to obtain three-dimensional porous carbonaceous material from biomass (fish seed) by pyrolysis and activation. The three-dimensional porous carbonaceous material is then fabricated as electrodes for a supercapacitor. Owing to fish seed being rich in elemental oxygen and nitrogen, the heteroatoms can introduce a pseudo-capacitance without doping. Scanning electron microscopy (SEM) analysis results show that the three-dimensional porous carbonaceous material exhibits an interconnected porous structure, which consists of micropores, mesopores and macropores. Adsorptiondesorption measurements determine that its surface area is $3232 \mathrm{~m}^{2} \cdot \mathrm{g}^{-1}$. Electrochemical measurements show that the biomass-derived porous carbon material displays a relatively high specific capacitance of $350 \mathrm{~F} \cdot \mathrm{g}^{-1}$ at $0.5 \mathrm{~A} \cdot \mathrm{g}^{-1}$ and an initial capacitance retention of $90.9 \%$ after 10,000 cycles in a threeelectrode system, where $\mathrm{KOH}(6 \mathrm{M})$ is used as the electrolyte. In addition, the porous carbon material is also tested in a two-electrode system and exhibits a specific capacitance of $250 \mathrm{~F} \cdot \mathrm{g}^{-1}$ at $1 \mathrm{~A} \cdot \mathrm{g}^{-1}$, and the specific capacitance retention reaches $94 \%$ after 10,000 cycles at $10 \mathrm{~A} \cdot \mathrm{g}^{-1}$. Furthermore, the energy density of the supercapacitor is approximately $8.68 \mathrm{Wh} \cdot \mathrm{kg}^{-1}$ at a power density of $125 \mathrm{~W} \cdot \mathrm{kg}^{-1}$ in the two-electrode system.
\end{abstract}

Keywords: Biomass; Direct pyrolysis; Porous carbon; Supercapacitors

\section{$\underline{\text { FULL TEXT }}$}

(C) 2019 The Authors. Published by ESG (www.electrochemsci.org). This article is an open access article distributed under the terms and conditions of the Creative Commons Attribution license (http://creativecommons.org/licenses/by/4.0/). 